\title{
Corrigendum: The Rise of Populism and the Reconfiguration of the German Political Space
}

\author{
Eckehard Olbrich* and Sven Banisch \\ Max Planck Institute for Mathematics in the Sciences, Leipzig, Germany
}

Keywords: political space, network analysis, topic model (LDA), populism, party competition

Approved by:

Frontiers Editorial Office,

Frontiers Media SA, Switzerland

*Correspondence:

Eckehard Olbrich

olbrich@mis.mpg.de

Specialty section: This article was submitted to

Big Data Networks,

a section of the journal

Frontiers in Big Data

Received: 10 December 2021 Accepted: 15 December 2021

Published: 11 January 2022

Citation:

Olbrich E and Banisch S (2022) Corrigendum: The Rise of Populism

and the Reconfiguration of the

German Political Space.

Front. Big Data 4:833037.

doi: 10.3389/fdata.2021.833037 


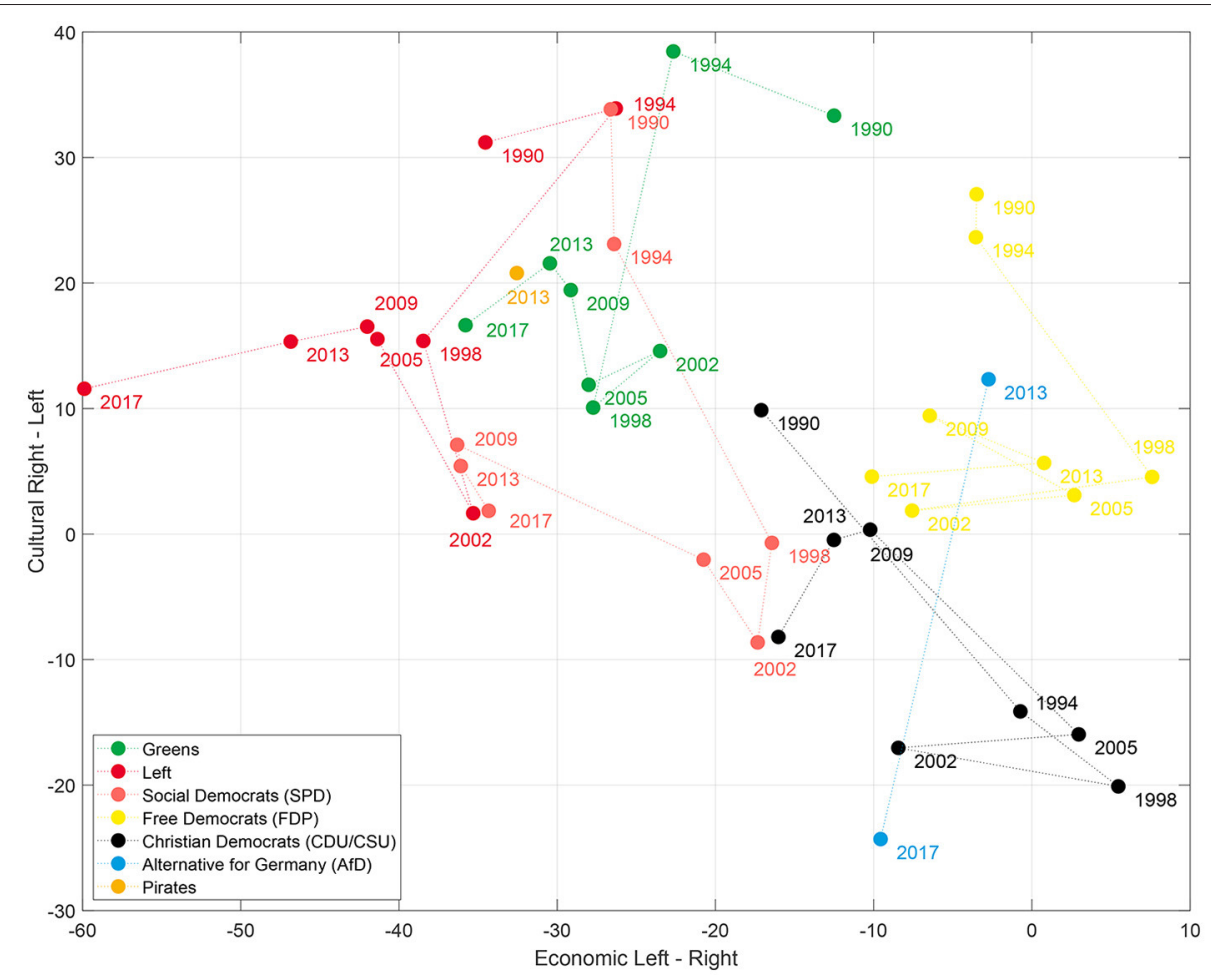

FIGURE 2 | Projection on the 2-days political space with the economic and cultural axis spanned by the difference between the economic and cultural left and right categories, respectively (see Table 5) of the German parties between 1998 and 2017.
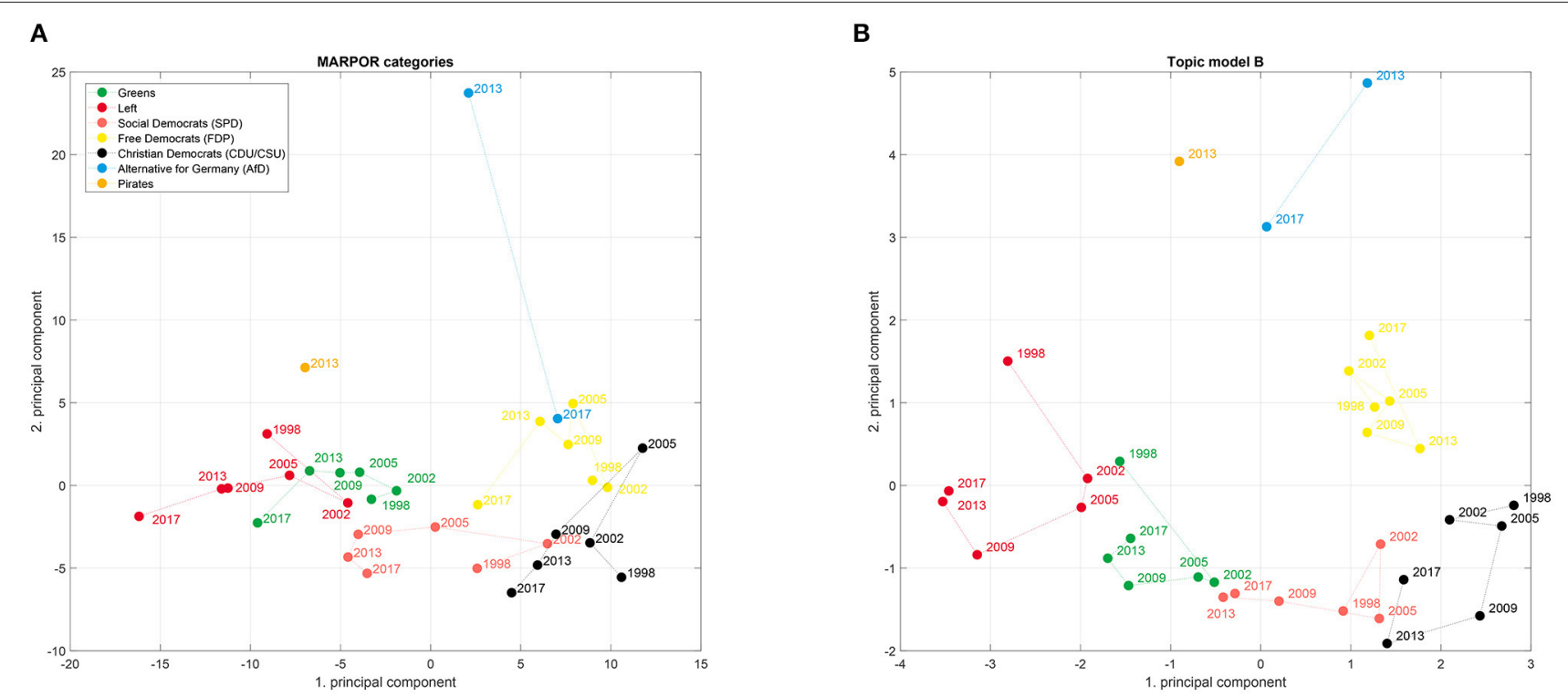

FIGURE 3 | Political spaces spanned by the first and second PCA component from the MARPOR counts (A) and for the topic model B (B) for Germany $1998-2017$. 